\section{CITAÇÃO}

Corrêa, C. (2016)

Deslocalização eletrónica,

Rev. Ciência Elem., V4(01):009.

doi.org/10.24927/rce2016.009

\section{EDITOR}

José Ferreira Gomes,

Universidade do Porto

\section{COPYRIGHT}

(C) Casa das Ciências 2018.

Este artigo é de acesso livre, distribuído sob licença Creative Commons com a designação CC-BY-NC-SA 4.0, que permite a utilização e a partilha para fins não comerciais, desde que citado 0 autor e a fonte original do artigo.

\section{rce.casadasciencias.org}

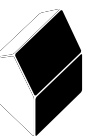

\title{
Deslocalização eletrónica
}

\section{Carlos Corrêa \\ Universidade do Porto \\ ccorrea@fc.up.pt}

\section{Ressonância ou mesomerismo.}

Em certos casos não é possível representar corretamente a estrutura de um composto por uma única fórmula de estrutura de Lewis, tendo de se recorrer a várias fórmulas que, no seu conjunto, segundo a teoria da ligação de valênca, representam a verdadeira estrutura da molécula. É o caso do ozono (FIGURA 1), formado por 3 átomos de oxigénio, com geometria angular e comprimentos de ligação de 128 pm, intermédio entre os comprimentos da ligação dupla $0=0(121 \mathrm{pm})$ e da ligação simples 0-0 (148 pm). Os dois oxigénio extremos apresentam igual carga negativa (cerca de $-0,1$ ) e 0 átomo central uma carga positiva próxima de $+0,2$.

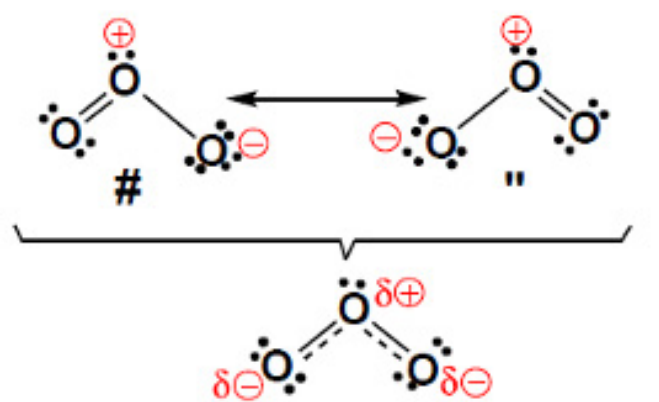<smiles></smiles>

FIGURA 1. Estruturas contribuintes do ozono. Comprimentos de ligação 0-0.

ESe utilizássemos uma só fórmula de estrutura ( $A$ ou $B$ ) para representar o ozono, as duas ligações $0-0$ teriam comprimentos diferentes, o que não se verifica experimentalmente. Analogamente, dadas as cargas formais representadas, a carga $\boldsymbol{\delta}->$ devia localizar-se no átomo de oxigénio terminal da ligação dupla e não distribuir-se igualmente pelos dois oxigénios terminais.

O ozono tem características de $\mathbf{A}$ e de $\mathbf{B}$ mas não é A nem B. A primeira ligação 0-0 não é dupla (como indica $\mathbf{A}$ ) nem simples, como indica $\mathbf{B}$. Tem caráter intermédio entre ligação dupla e ligação simples, digamos de ordem 1,5 , como mostra a fórmula debaixo da chaveta na FIGURA 1. As fórmulas de estrutura de Lewis, com eletrões localizados, não permitem representar adequadamente o composto. De acordo com a teoria da liga- 
ção de valência, a verdadeira estrutura tem, assim, de ser representada pelo conjunto de fórmulas de estrutura $\mathbf{A}$ e $\mathbf{B}$.

Diz-se que estamos perante um híbrido de ressonância; as fórmulas $\mathbf{A}$ e $\mathbf{B}$ denominam-se estruturas contribuintes, e unem-se pelo sinal $\leftrightarrow$, que não traduz equilíbrio mas sim mesomerismo ou ressonância.

0 ácido nítrico, o dióxido de azoto e muitos outros, constituem casos semelhantes (FIGURA 2). No dióxido de azoto, $\mathrm{NO}_{2}$, as estruturas contribuintes mostram que as cargas se distribuem sobre os átomos de azoto e de oxigénio e o eletrão desemparelhado (o composto é um radical livre) se associa aos átomos de azoto e de oxigénio. Analogamente, o caráter "radical" estende-se pelos 3 átomos.
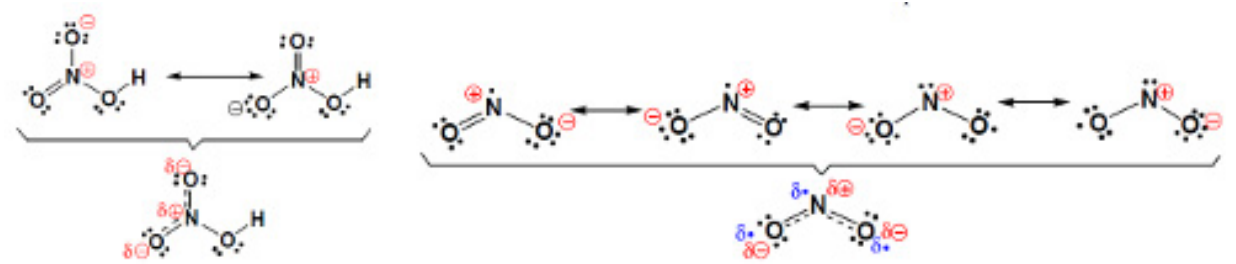

FIGURA 2. Estruturas contribuintes do ácido nítrico e dióxido de azoto.

Em todos estes exemplos há eletrões que se distribuem sobre vários átomos em vez de se localizarem num único átomo. Esses eletrões dizem-se deslocalizados e o fenómeno designa-se por deslocalização eletrónica. A deslocalização eletrónica é muito importante em Química, pois os sistemas em que ela ocorre apresentam maior estabilidade, o que tem consequências sobre a reatividade das partículas.

\section{0 Catião alilo.}

0 catião alilo, $\mathrm{CH}_{2}=\mathrm{CH}-\mathrm{CH}_{2}{ }^{+}$, é um híbrido de ressonância com as seguintes estruturas contribuintes (FIGURA 3):

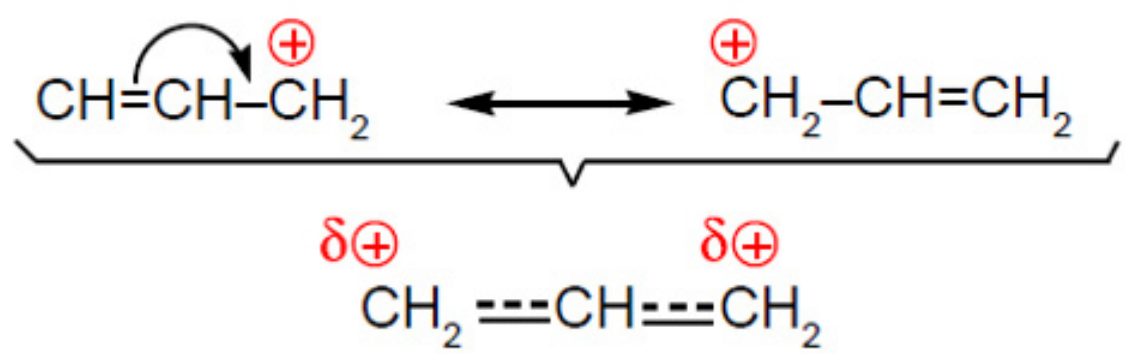

FIGURA 3. Estruturas contribuintes para o catião alilo.

O catião é algo semelhante ao que está representado sob a chaveta. Não há ligações simples e duplas entre os átomos de carbono mas antes ligações intermédias, isto é, a ordem das ligações é 1,5. De igual modo, a carga não se localiza num carbono terminal mas antes nos dois carbonos terminais, igualmente distribuída. 
Note-se que as estruturas contribuintes representam diferentes distribuições eletrónicas sobre um mesmo esqueleto molecular que se mantém inalterado (os núcleos dos diferentes átomos mantêm a mesma posição).

\section{Orbitais moleculares.}

A deslocalização eletrónica pode também ser tratado pela teoria das orbitais moleculares. Recorde-se que as orbitais moleculares (OM) se formam pela combinação linear de orbitais atómicas (AO); a partir de $n$ AO obtêm-se $n$ OM.
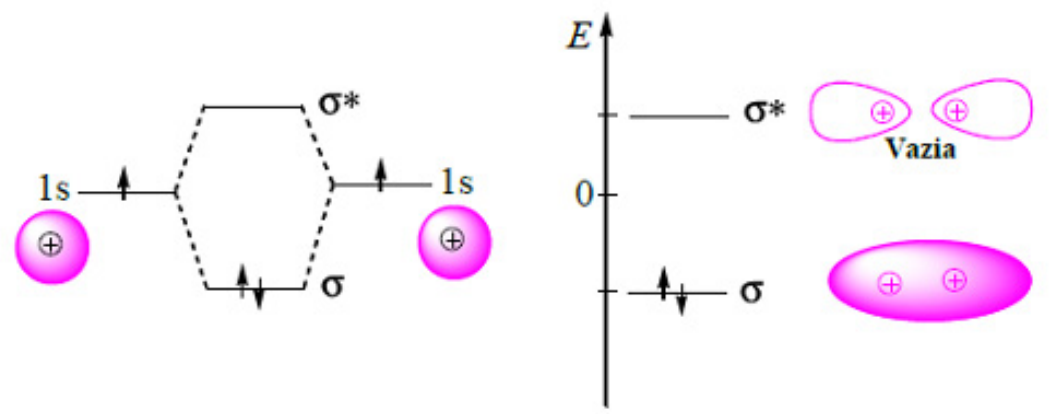

FIGURA 4. Orbitais atómicas e moleculares da molécula $\mathrm{H}_{2}$

Recordemos que a partir de duas orbitais atómicas do hidrogénio (FIGURA 4) se obtêm duas orbitais moleculares da molécula $\mathrm{H}_{2}$, uma OM ligante e outra antiligante $\left(\sigma\right.$ e $\left.\sigma^{\star}\right)$. Os eletrões da ligação $\sigma$ estão localizados, isto é, envolvem somente dois núcleos.

No catião alilo os eletrões deslocalizados são eletrões da ligação dupla, ou seja eletrões $\pi$. A ligação dupla $\mathrm{C}=\mathrm{C}$ é constituída por uma ligação simples $\sigma$ e por uma ligação $\pi$, obtida a partir de $\mathrm{AO} \mathrm{p}_{\mathrm{z}}$ dos carbonos, como se mostra para o propeno (FIGURA 5).

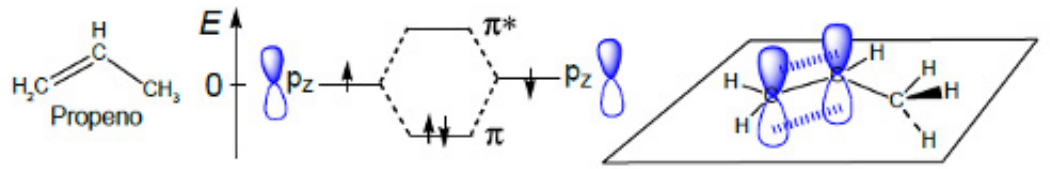

FIGURA 5. Formação de orbitais moleculares $\pi$ do propeno.

0 catião alilo pode derivar-se do propeno por remoção de hidreto do grupo metilo. Neste caso, além das duas $A O p_{z}$ dos carbonos 1 e 2, temos no carbono 3 uma nova $A O p_{z}$ para entrar no jogo. Da combinação das três orbitais atómicas pz resultam três orbitais moleculares $\pi$, de energias diferentes (FIGURA 6). A de energia mais baixa é a OM ligante, $\mathrm{OML}$, que está totalmente preenchida. A orbital de energia mais alta é uma OM antiligante, OMAL, e de energia intermédia é a OM não ligante, OMNL, ambas vazias. 

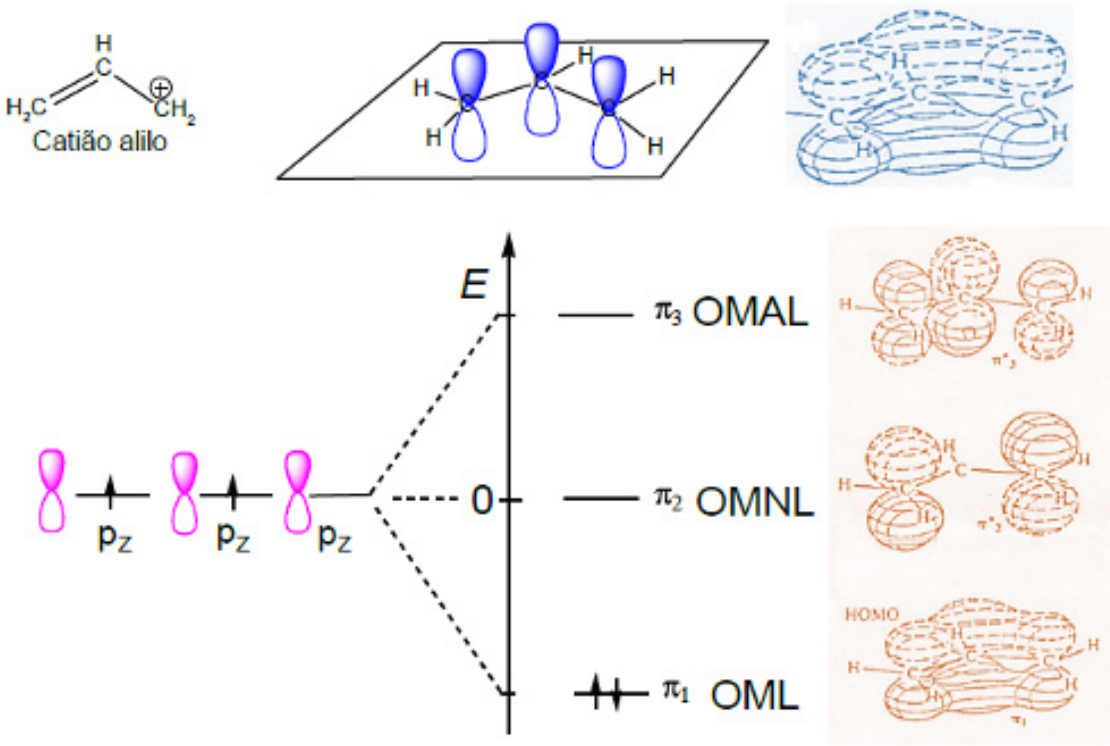

FIGURA 6. Orbitais moleculares do catião alilo.

A orbital molecular ligante, de energia mínima, completamente preenchida, permite verificar que os dois eletrões $\pi$ se deslocalizam sobre os três núcleos dos átomos de carbono. Além disso, a energia dos dois eletrões diminuiu, quer dizer, o sistema deslocalizado é mais estável que o não deslocalizado. É possível calcular as densidades eletrónicas nos diferentes átomos de carbono e verificar que a carga positiva se distribui igualmente sobre os dois carbonos extremos, como era descrito pelo tratamento por ressonância.

Neste carbocatião, a $\mathrm{OM} \pi_{2}$ está vazia; se contiver um eletrão, tem-se o radical alilo e se estiver completamente preenchida obtém-se o carbanião alilo.

\section{Estabilização por deslocalização eletrónica.}

A estabilidade dos carbocatiões, dos carbaniões e dos radicais livres aumenta apreciavelmente quando há deslocalização eletrónica, o que vai ter importantes consequências na reatividade destes intermediários.

A diminuição da energia de dissociação heterolítica (FIGURA 7, a vermelho) para formar carbocatiões quando se passa do propano para o propeno e do metilciclo-hexano para 0 tolueno resulta da maior estabilização dos carbocatiões formados. 0 mesmo se passa com a energia de dissociação para formar radicais (a azul) e acidez, de acordo com a maior estabilização dos radicais e dos carbaniões produzidos.
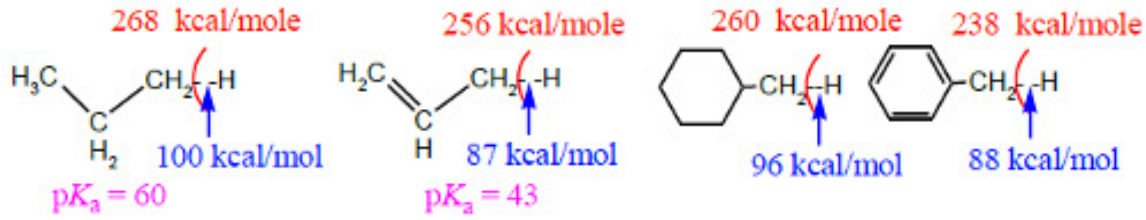

FIGURA 7. Comparação das energias de dissociação heterolítica e homolítica e acidez em compostos semelhantes. 
A fraca acidez dos hidrocarbonetos ( $\mathrm{pK}_{\mathrm{a}}$ da ordem de meia centena) é aumentada por muitas potências de 10 quando há possibilidade de deslocalização da carga negativa do anião resultante da protólise (FIGURA 8). Por isso o ciclopentadieno é muitíssimo mais acido que 0 ciclopentano $\mathrm{e} a$ acidez do tolueno vai aumentando à medida que se aumenta $\mathrm{o}$ número de anéis ligados ao carbono alifático.

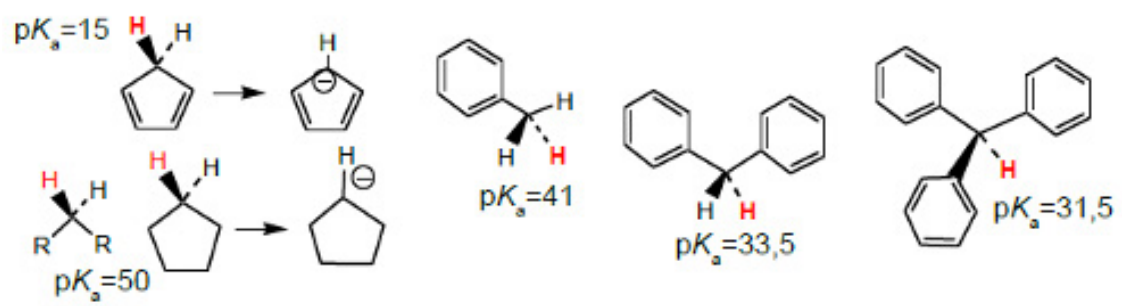

FIGURA 8. Efeito da deslocalização eletrónica na acidez de compostos semelhantes

Os alcenos conjugados são mais estáveis do que os que têm as ligações duplas afastadas. Consideremos um hidrocarboneto com duas ligações duplas afastadas entre si, por exemplo o penta-1,5-dieno, $\mathrm{CH}_{2}=\mathrm{CH}-\mathrm{CH}_{2}-\mathrm{CH}=\mathrm{CH}_{2}$ (FIGURA 9). Se hidrogenarmos o composto, o calor de reação será duplo do calor de hidrogenação de um alceno terminal, cerca de $2 \times 30 \mathrm{~kJ} / \mathrm{mol}$. No entanto, se as ligações duplas estiverem conjugadas, o calor de hidrogenação é inferior devido à estabilização $\Delta \Delta H$ resultante da deslocalização eletrónica. Em termos de ressonância, as estruturas contribuintes mostram uma deslocalização eletrónica que confere caráter duplo à ligação entre os carbonos 2 e 3 e não mostra uma distribuição assimétrica de carga, de acordo com as propriedades do composto.
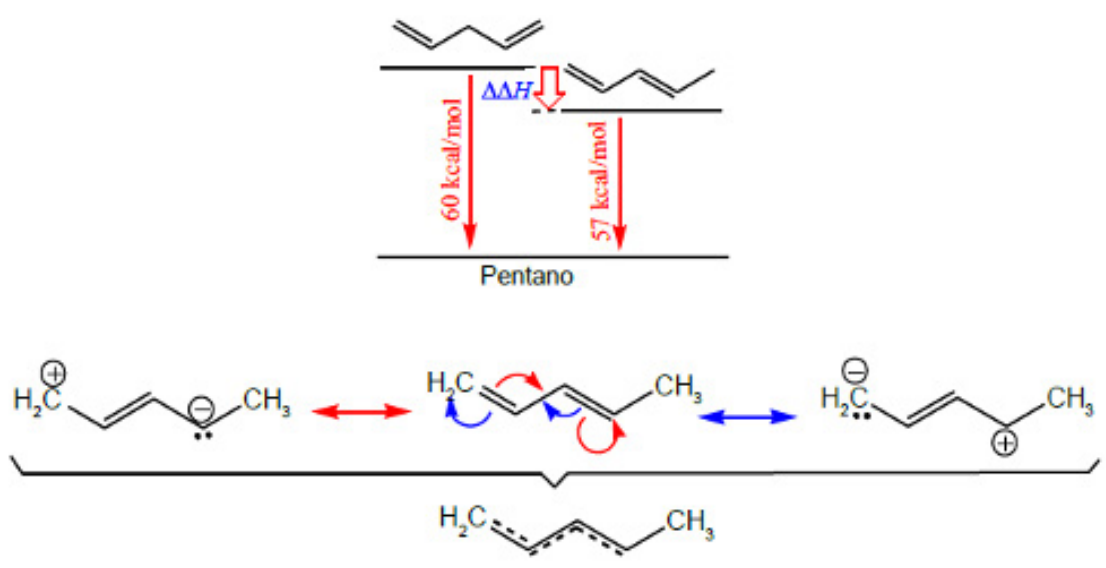

FIGURA 9. Energias de hidrogenação e estruturas contribuintes do penta-1,3-dieno.

Em termos de orbitais moleculares, as quatro $\mathrm{OA} \mathrm{p}_{\mathrm{z}}$ combinam-se e originam quatro $\mathrm{OM}$ $\Psi 1, \Psi 2, \Psi 3$ e $\Psi 4$ de diferentes energias (FIGURA 10). Os quatro letrões $\pi$ ocupam as duas $\mathrm{OM}$ de energia mais baixa e estendem-se sobre os quatro átomos de carbono, o que se traduz numa extensa deslocalização eletrónica. As ligações $C_{2}-C_{3}$ passaram a ter um certo 
caráter duplo (2 eletrões $\pi$ para três ligações $C C$ ), enquanto as ligações $C_{1}-C_{2}$ e $C_{3}-C_{4}$ perderam um pouco desse carater (2 eletrões $\pi$ para duas ligações $\mathrm{CC}$ ). Note-se que a energia do sistema $\pi$ agora é menor, ou seja, a deslocalização eletrónica estabilizou o sistema.
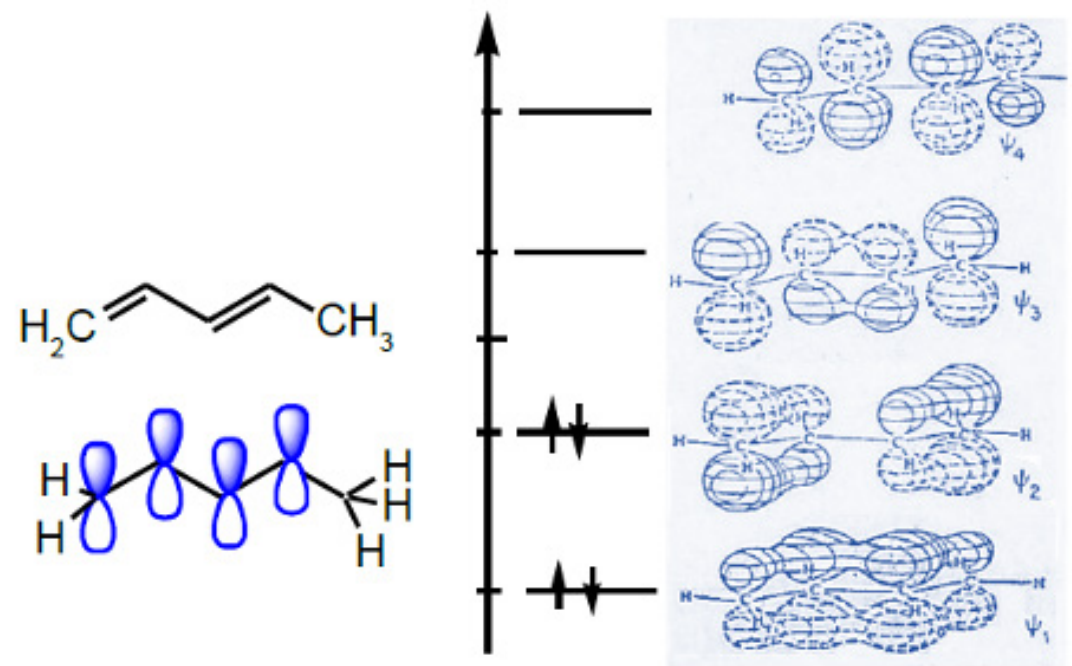

FIGURA 10. Energias de hidrogenação e estruturas contribuintes do penta-1,3-dieno.

\section{Benzeno. Aromaticidade.}

A estabilização decorrente da deslocalização eletrónica pode ser evidenciada de várias formas, nomeadamente por comparação das energias de hidrogenação dos compostos, como se viu já.

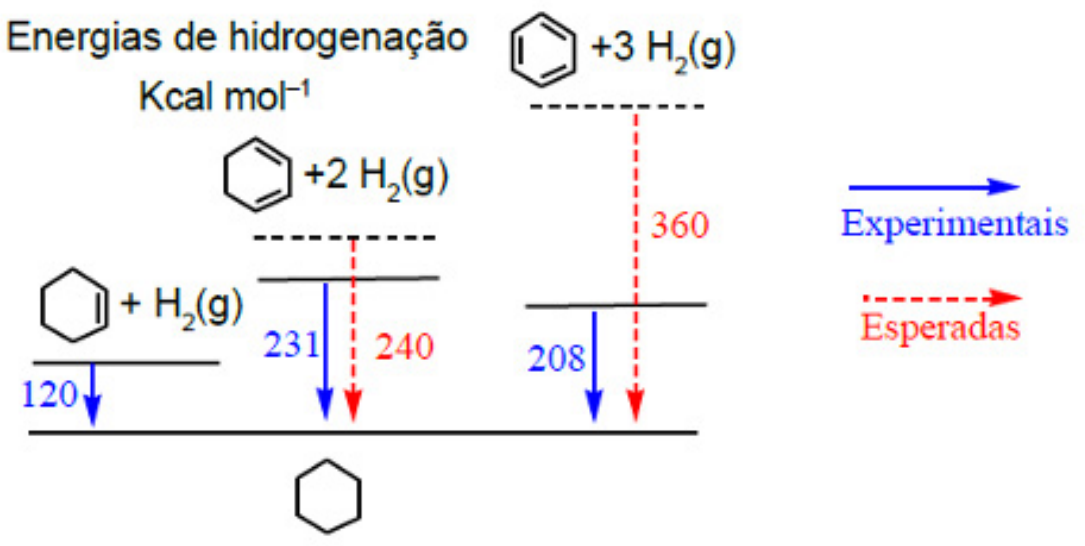

FIGURA 11. Energias de hidrogenação de uma, duas e três ligações duplas.

A energia de hidrogenação do ciclo-hexadieno (com duas ligações duplas) deveria ser aproximadamente o dobro da correspondente energia do ciclo-hexeno (uma só ligação dupla) se não fosse a estabilização devido à conjugação (FIGURA 11). Na realidade, esta energia, aparte o sinal, vale $231 \mathrm{kcal} / \mathrm{mol}$ em vez de $2 \times 120 \mathrm{kcal} / \mathrm{mole}$, revelando uma es- 
tabilização de cerca de $9 \mathrm{kcal} / \mathrm{mol}$. A energia de hidrogenação do benzeno, supostamente com três ligações duplas, dada a deslocalização eletrónica, deveria ser inferior a $3 \times 120$ $\mathrm{kcal} / \mathrm{mole}$, mas verifica-se que é muitíssimo inferior (208 kcal/mol) devido à excecional estabilização do enzeno. Esta extensa estabilização ocorre em sistemas ditos aromáticos, como o benzeno, que se caraterizam por conter $4 n+2$ eletrões $\pi(2,6,10,14$, etc.) deslocalizados num ou mais anéis. Como vimos, o anião ciclopentadienilo (FIGURA 12), base conjugada do ciclopentadieno, deve a sua elevada estabilidade à aromaticidade que exibe (6 eletrões $p$ deslocalizados num anel).

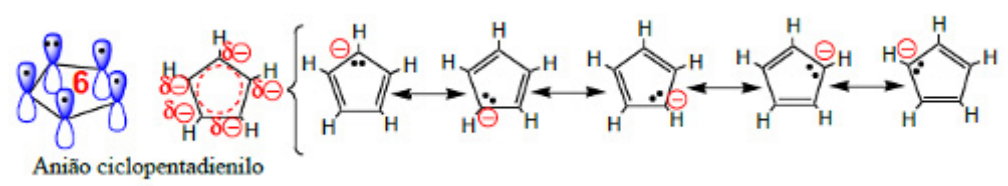

FIGURA 12. Anião ciclopentadienilo. Eletrões $\pi$ e estruturas contribuintes.

Além dos hidrocarbonetos aromáticos polinucleares comuns, como o naftaleno, o antraceno e o fenantreno, existem outros compostos e iões que apresentam aromaticidade (FIGURA 13).<smiles>c1ccccc1</smiles>
Benzeno<smiles>[c-]1ccccc1</smiles>
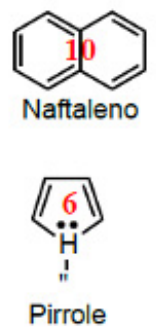<smiles>CC(=O)c1cccc2cc3ccccc3cc12</smiles><smiles>O=c1cc2ccccc2cc2c1ccc1ccccc12</smiles>

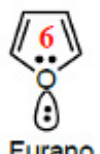

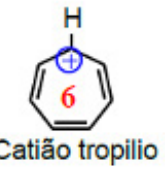

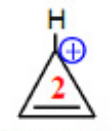

Catião ciclopropenilo

FIGURA 13. Sistemas aromáticos, com indicação do número de eletrões $\pi$. 